\title{
Research Article \\ Offset Optimization Based on Queue Length Constraint for Saturated Arterial Intersections
}

\author{
Xianmin Song, ${ }^{1}$ Pengfei Tao, ${ }^{1}$ Ligang Chen, ${ }^{1}$ and Dianhai Wang ${ }^{2}$ \\ ${ }^{1}$ Transportation College, Jilin University, Changchun 130022, China \\ ${ }^{2}$ Civil Engineering and Architecture College, Zhejiang University, Hangzhou 310058, China \\ Correspondence should be addressed to Xianmin Song, songxm@jlu.edu.cn
}

Received 17 August 2012; Revised 27 November 2012; Accepted 4 December 2012

Academic Editor: Wuhong Wang

Copyright (c) 2012 Xianmin Song et al. This is an open access article distributed under the Creative Commons Attribution License, which permits unrestricted use, distribution, and reproduction in any medium, provided the original work is properly cited.

Offset optimization is of critical importance to the traffic control system, especially when spillovers appear. In order to avoid vehicle queue spillovers, an arterial offset optimization model was presented in saturated arterial intersections based on minimizing the queue length over the whole duration of the saturated traffic environment. The paper uses the shockwave theory to analyze the queue evolution process of the intersection approach under the saturated traffic environment. Then through establishing and analyzing a function relationship between offset and the maximum queue length per cycle, a mapping model of offset and maximum queue length was established in the saturated condition. The validity and sensitivity of this model were tested by the VISSIM simulation environment. Finally, results showed that when volumes ratios are $0.525-0.6$, adjusting offset reasonably under the saturated condition could decrease the queue length and effectively improve the vehicle operating efficiency.

\section{Introduction}

In arterials systems, reasonable adoption of the coordinated control could decrease vehicle delays and stops. Offset is an important parameter of the arterial signal coordinate control, which decides the effect of the coordinated control for adjacent intersections. Now, there are mainly two kinds of the offset optimization [1-3]: (1) Maximum Green Wave Band, setting offset in order to obtain green wave travel time (maximize ratio of the green wave band width to cycle length). It includes Graphical Method, Mathematical Analysis Method, and Max Band Method; (2) minimize vehicle delays and/or stops, optimizing offset by an index function relation between the vehicle delays (stops) and offset.

The above arterial coordination methods play an important role in the practical traffic management. However, these methods are mainly designed to the undersaturated coordination, namely, link supply can satisfy upstream input demand [4]. With the increasing of 
vehicle year by year, the saturated state of the arterial system becomes more common. If we use the above methods to analyze the saturated condition, we would obtain misleading results. Therefore, the study of offset optimization at the saturated arterial has important theoretical significance and application value.

When traffic demand exceeds road capacity or intersection capacity, the saturated condition appears, and vehicle queues continue to increase. These queues can overflow the storage capacity of the road and physically block intersections and gradually spread to the surrounding intersections. Implementing signal control policies designed for the undersaturated condition is ineffective and even counters product to the saturated condition [5-7]. Therefore, carrying on traffic dispersion and decreasing the queue length are major signal control objectives of the saturated environment. Now, the study of the saturated arterial signal coordinated control mainly included the following three categories: (1) maximum system capacity, based on an optimization objective of maximum release amount of system; Khatib and Judd [8] gave a corresponding control strategy, and Ghassan and Rahim [9] conducted coordinate control based on a control objective of the system turn over volumes. (2) Minimize vehicle delays or stops: an optimization strategy [10-12] mainly analyzes traffic delay of traveling team over the whole duration for the saturated traffic environment, then an arterial offset optimization model was presented based on an objective of minimizing delay or queue length. (3) Control queue length: Chang and Lin [13] proposed a saturated traffic control method, which managed the queuing dissipation and formation in subarea sections, and Lieberman et al. [14] proposed a method to optimize queue length based on the saturated arterial coordinate control strategy. Wang et al. $[15,16]$ put pedestrian safety as an important factor in coordinated system. However, this paper is focused on the theoretical models per cycle; there is no optimal control of the maximum queue length for multiple consecutive cycles.

According to an objective of minimizing queue length over the whole duration of the saturated traffic environment, the paper presented a method to optimize offset of the saturated arterial through analyzing queue evolution process based on shockwave theory. Through establishing and analyzing functions relationship between offset and maximum queue length of single cycle, a mapping model of offset and maximum queue length is established in the saturated condition. Finally, validity and sensitivity of the model are tested in VISSIM software.

\section{The Queue Evolution Process of the Saturated Traffic Environment}

\subsection{State Description of the Saturated Arterial}

When traffic demand is much more than the capacity at saturated arterial intersections, the number of in-flowing vehicles exceeds those discharging from the approach, and queue length will gradually increase at downstream intersection. Assuming the signal timing parameters remain fixed, this current state of the approach will sustainably develop, then the long queuing will spill over to the upstream intersection. Our study is based on the following basic assumptions.

(1) Saturated arterial intersections are typical four phases, and the phase sequence remains consistent and fixed. Every cycle is composed of the green time and red time without considering the yellow time. Right-turn flows at the adjacent intersection are less and without signal control, so that its effect can be neglected. Figure 1 shows the main direction of traffic flows and phase sequence at saturated arterial adjacent intersections, in which east-west through phase is coordination phase. 


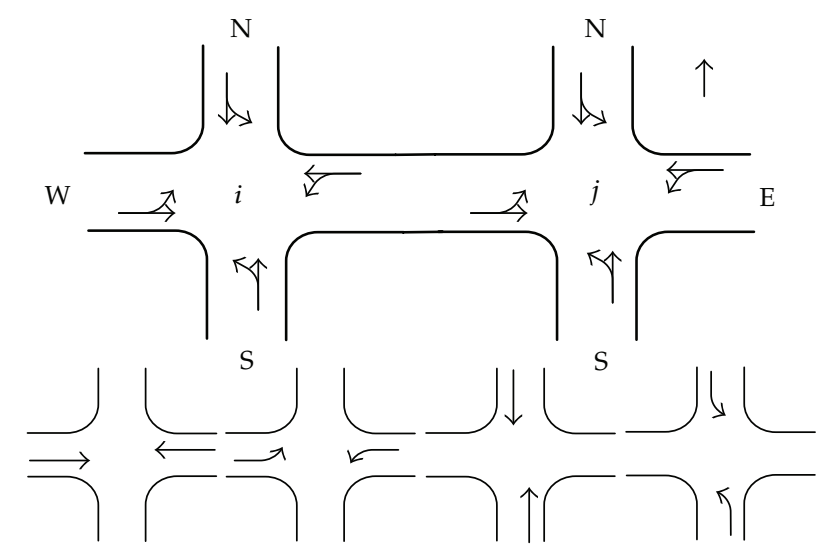

Figure 1: Main direction of traffic flows and phase-sequence at saturated arterial adjacent intersections.

As shown in Figure 1, $i$ is upstream intersection, while $j$ is downstream intersection. Arrival vehicle of intersection $j$ is downstream that consists of two parts: west approach through flows and north approach left-turn flows of upstream intersection. The number of arrival vehicles per cycle of downstream intersection is

$$
Q_{\mathrm{W}}(j)=D_{\mathrm{W}}(i)\left[1-p_{\mathrm{W}}(i)\right] g_{\mathrm{WES}}(i)+D_{N}(i) p_{\mathrm{N}}(i) g_{\mathrm{NEL}}(i),
$$

where $Q_{W}(j)$ is the number of arrival vehicles per cycle of downstream intersection; $D_{\mathrm{W}}(i)$ and $D_{\mathrm{N}}(i)$ are west approach and north approach discharge rate of intersection $j ; p_{\mathrm{W}}(i)$ and $p_{\mathrm{N}}(i)$ are west approach and north approach turning movement proportions of intersection $j ; g_{\mathrm{WES}}(i)$ and $g_{\mathrm{NSL}}(i)$ are east-west straight and south-north left-turn phase green time.

(2) Coordination phase green time of upstream intersection is adequate. When green time starts, the platoon firstly discharges with saturation flow rate, and later discharges with average arrival rate. If we ignore the discreteness of platoon to reach downstream intersection, the travel platoon will be pulse arriving to downstream:

$$
D(i)= \begin{cases}S, & 0<t \leq g_{s}(i), \\ q_{\mathrm{W}}(i), & g_{s}(i)<t \leq g_{\mathrm{WES}}(i),\end{cases}
$$

where $q_{\mathrm{W}}(i)$ and $D(i)$ are the arrival and discharge rates of upstream intersection coordination phase; $S$ is the saturation flow rate; $g_{S}(i)$ is the duration of saturation discharging of upstream intersection coordination phase. The duration of saturation discharging is

$$
g_{s}(i)=\frac{\left(C-g_{\mathrm{WES}}(i)\right) \cdot q_{\mathrm{W}}(i)}{S-q_{\mathrm{W}}(i)}
$$

Then there are three femoral pulses of the travel platoons, as Figure 2 showed. Substituting (2.2) into (2.1), then

$$
Q_{\mathrm{W}}(j)=\left[S g_{s}(i)+q_{\mathrm{W}}(i)\left(g_{\mathrm{WES}}(i)-g_{s}(i)\right)\right]\left[1-p_{\mathrm{W}}(i)\right] g_{\mathrm{WES}}(i)+D_{\mathrm{N}}(i) p_{\mathrm{N}}(i) g_{\mathrm{NEL}}(i)
$$




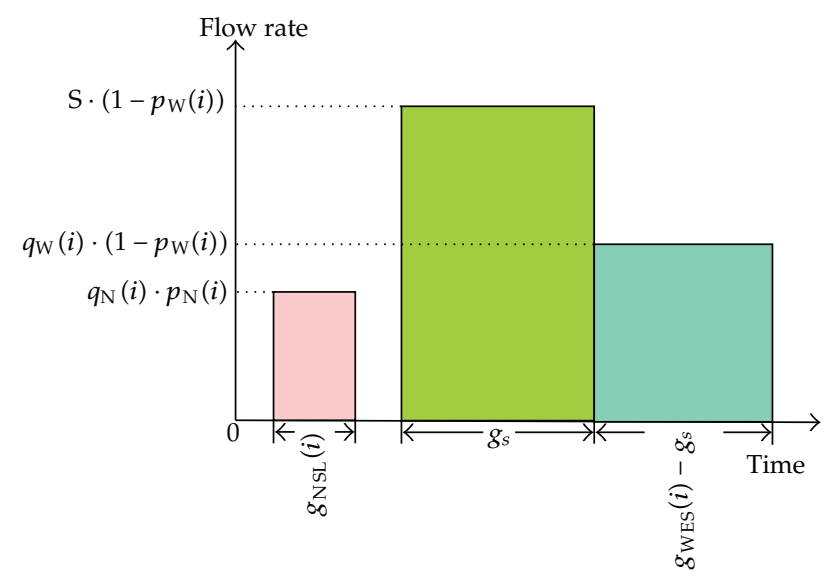

Figure 2: Pulse arrival flows schema of downstream intersection.

(3) Maximum cycle length model to determine intersection cycle [17]:

$$
C=\sqrt{\frac{L T}{(1-\omega) Y}}
$$

where $C$ is the cycle time; $L$ is the total loss time; $T$ is the duration of saturated conditions; $Y$ is the total flow ratio.

(4) The common cycle length of the saturated arterial is determined by traditional methods [18], and the numbers of the saturated cycles can be calculated as follows:

$$
\delta=\left\lceil\frac{T}{C_{o}}\right\rceil
$$

where $C_{o}$ is the common cycle length.

(5) Green time of each intersection allocated by equal saturation principle.

\subsection{Queue Evolution Analysis}

At a signalized intersection, multiple shock waves are generated due to the stop-and-go traffic caused by signal changes. As indicated in Figure 3, when upstream intersection green time starts, the platoon firstly discharging of saturation flow rate $S$ discharges to downstream intersection. The head vehicle of platoon forced to stop at downstream intersection because of red time, at which it creates different flows and density conditions between the arrival and stopped traffic, forms a queuing shockwave:

$$
v_{1}=\frac{q_{a}^{1}}{k_{j}-k_{a}^{1}}
$$




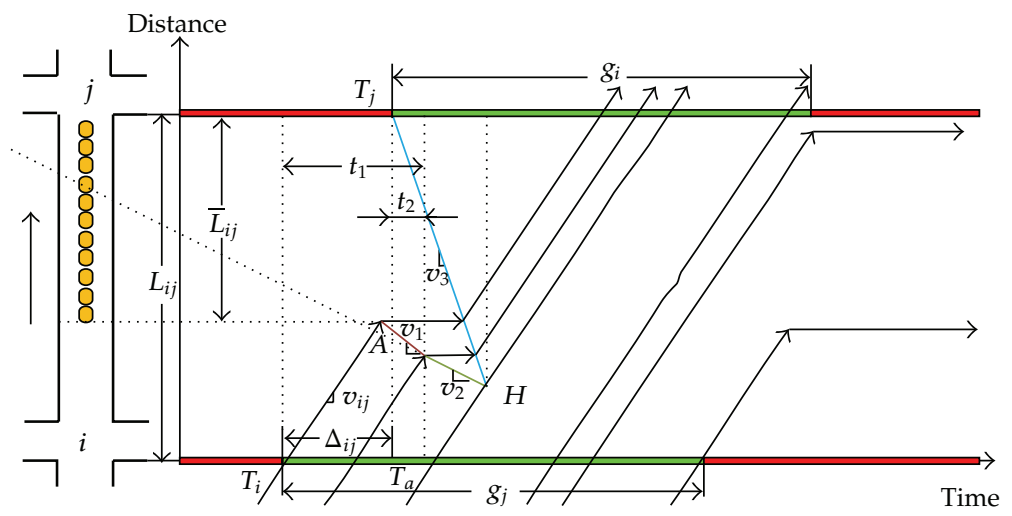

Figure 3: Traffic flow temporal-spatial graph at saturated arterial adjacent intersections.

where $k_{j}$ represents the jammed density; $q_{a}^{1}$ and $k_{a}^{1}$ are the average arrival flow rates and density of first part flows; $q_{a}^{1}$ and $k_{a}^{1}$ can be calculated as [19]

$$
\begin{gathered}
q_{a}^{1}=S \cdot \frac{g_{s}(i)}{C_{o}} \\
k_{a}^{1}=\frac{q_{a}^{1}}{v_{i j}} .
\end{gathered}
$$

Substituting (2.8) into (2.7), then

$$
v_{1}=\frac{S \cdot h \cdot g_{s}(i) \cdot v_{i j}}{1000 C_{o} \cdot v_{i j}-S \cdot h \cdot g_{s}(i)}
$$

where $h$ is mean queue discharge headway.

When arrival vehicles are of the saturation flow rate all joining the queue, the second part flows will continue to queue, forming a queuing shockwave:

$$
v_{2}=\frac{q_{\mathrm{W}}(i) \cdot h \cdot\left(g_{\mathrm{WES}}(i)-g_{s}(i)\right) \cdot v_{i j}}{1000 C_{o} \cdot v_{i j}-q_{\mathrm{W}}(i) \cdot h \cdot\left(g_{\mathrm{WES}}(i)-g_{s}(i)\right)} .
$$

Similarly, at the beginning of the downstream intersection green, vehicles begin to discharge of the saturation flow rate forming a discharge shockwave:

$$
v_{3}=\frac{S \cdot h \cdot g_{s}(j) \cdot v_{i j}}{1000 C_{o} \cdot v_{i j}-S \cdot h \cdot g_{s}(j)}
$$

$v_{1}, v_{2}, v_{3}$ all moved upstream of the intersection and finally intersected at point $H$, which is the point of maximum queue length. 


\section{Offset Optimization for the Saturated Arterial}

\subsection{Single Cycle Function Relationship between Offset and Maximum Queue Length}

Figure 3 shows the operating condition of adjacent intersections flows. At the beginning of the downstream intersection green, head vehicle is of average speed $v_{i j}$ traveling to the downstream intersection and joins the end of original queue in which speed reduces to 0 . Until the discharge shockwave of downstream intersection spreads to this location, head vehicle continues to travel downstream of average speed $v_{i j}$. Subsequently the following head vehicles that arrive before point $H$ are in such process $\left(v_{i j} \rightarrow 0 \rightarrow v_{i j}\right)$ running in the link. After point $H$, arrive vehicles travel downstream of average speed unimpeded. The above process is shown in Figure 3. According to Figure 3, offset can be represented as

$$
\phi_{i j}=t_{1}-t_{2}
$$

where $\phi_{i j}$ is the offset of intersection $i, j . t_{1}$ and $t_{2}$ can be calculated as

$$
\begin{gathered}
t_{1}=g_{S}(i)+\frac{L_{i j}-\left(Q_{i j}+S \cdot g_{s}(i)\right) \cdot h}{v_{i j}}, \\
t_{2}=\frac{\left(Q_{i j}+S \cdot g_{s}(i)\right) \cdot h}{v_{2}}-N_{i j} \cdot h\left(\frac{1}{v_{2}}-\frac{1}{v_{3}}\right),
\end{gathered}
$$

where $Q_{i j}$ is the original queue numbers of intersection $i, j$, veh; $N_{i j}$ is the maximum queue numbers of intersection $i, j$, veh. Substituting (3.2) into (3.1), then

$$
\phi_{i j}=g_{s}(i)+\frac{L_{i j}}{v_{i j}}+N_{i j} \cdot h\left(\frac{1}{v_{2}}-\frac{1}{v_{3}}\right)-\left(Q_{i j}+S \cdot g_{s}(i)\right) \cdot h\left(\frac{1}{v_{i j}}+\frac{1}{v_{2}}\right) .
$$

The maximum queue length of intersection $i, j$ can be represented as (15) is a computation model of maximum queue numbers per cycle. This model should be operated with the following two situations.

(1) When $\phi_{i j}>\left(L_{i j}-Q_{i j} \cdot h\right) / v_{i j}-Q_{i j} \cdot h / v_{3}$, maximum queue numbers per cycle and offset, common cycle, green time, original queue numbers, arrival rate, and discharge rate have a close relationship.

(2) When $\phi_{i j} \leq\left(L_{i j}-Q_{i j} \cdot h\right) / v_{i j}-Q_{i j} \cdot h / v_{3}$, maximum queue numbers equal to original queue numbers, arrival rate. Although this time of queue numbers is the shortest, it will result in the loss of downstream intersection green, not considered this situation:

$$
N_{i j}= \begin{cases}\frac{\left[\phi_{i j}-g_{s}(i)-L_{i j} / v_{i j}+\left(Q_{i j}+S \cdot g_{s}(i)\right) \cdot h\left(1 / v_{i j}+1 / v_{2}\right)\right]}{h \cdot\left(1 / v_{2}-1 / v_{3}\right)}, & \phi_{i j}>\frac{L_{i j}-Q_{i j} \cdot h}{v_{i j}}-\frac{Q_{i j} \cdot h}{v_{3}}, \\ Q_{i j}, & \phi_{i j} \leq \frac{L_{i j}-Q_{i j} \cdot h}{v_{i j}}-\frac{Q_{i j} \cdot h}{v_{3}} .\end{cases}
$$




\subsection{Computation Model of Queue Length Diversification}

Under the saturated condition, if the signal timing is fixed, the arrival rate and discharge rate stability, the maximum queue numbers, and original queue numbers are greater than previous cycles, and the relation of queue lengths between cycle $k$ and $k+1$ can be represented by the following equations:

$$
\begin{aligned}
Q_{i j}(k+1) & \geq Q_{i j}(k), \\
N_{i j}(k+1) & \geq N_{i j}(k) .
\end{aligned}
$$

The maximum queue numbers and original queue numbers of intersection $i, j$ are increased during the saturation period cycle by cycle, and reach the maximum in the last saturated cycle. We can get the law of queue length changes between adjacent cycles as shown in Figure 4. Ignore the disturbance of arrival and discharge; variable quantity of the original queue numbers can be calculated as

$$
\begin{aligned}
\Delta Q_{i j}= & {\left[S \cdot g_{s}(i)+q_{\mathrm{W}}(i) \cdot\left(g_{\mathrm{WES}}(i)-g_{s}(i)\right)\right] \cdot\left(1-p_{\mathrm{W}}(i)\right)+q_{\mathrm{N}}(i) \cdot p_{\mathrm{N}}(i) \cdot g_{\mathrm{NSL}}(i) } \\
& -\left[S \cdot g_{s}(j)+q_{\mathrm{W}}(j) \cdot\left(g_{\mathrm{WES}}(j)-g_{s}(j)\right)\right] \cdot\left(1-p_{\mathrm{W}}(j)\right) .
\end{aligned}
$$

An algorithm for solving the variable quantity of maximum queue numbers model is arranged in the following steps.

Step 1. By introducing parameter $t_{s}(k)$, which represents the residence time of head vehicle in the first part flows joining the end of original queue,

$$
t_{S}(k)=\Delta_{i j}(k)+\frac{Q_{i j}(k) \cdot h}{v_{1}}-\frac{L_{i j}-Q_{i j}(k) \cdot h}{v_{i j}} .
$$

There are continuous vehicles from upstream joining the queue; assuming queue residence time is $t_{s+1}(k), t_{s+2}(k), \ldots, t_{s+n-1}(k)$, then they are negatively correlated:

$$
t_{s+1}(k)>t_{s+2}(k)>\cdots>t_{s+n-1}(k)>0
$$

Step 2. The queue numbers of first part flows from upstream in cycle $k$ are

$$
n_{1}(k)=S \cdot g_{s}(i) \cdot\left(1-p_{\mathrm{W}}(i)\right) \text {. }
$$

Step 3. By introducing parameter $t_{s}^{\prime}(k)$, which represents the residence time of head vehicle in the second part flows joining the end of the original queue,

$$
t_{s}^{\prime}(k)=t_{s}(k)+n_{1}(k) \cdot h\left(\frac{1}{v_{3}}-\frac{1}{v_{1}}\right) .
$$




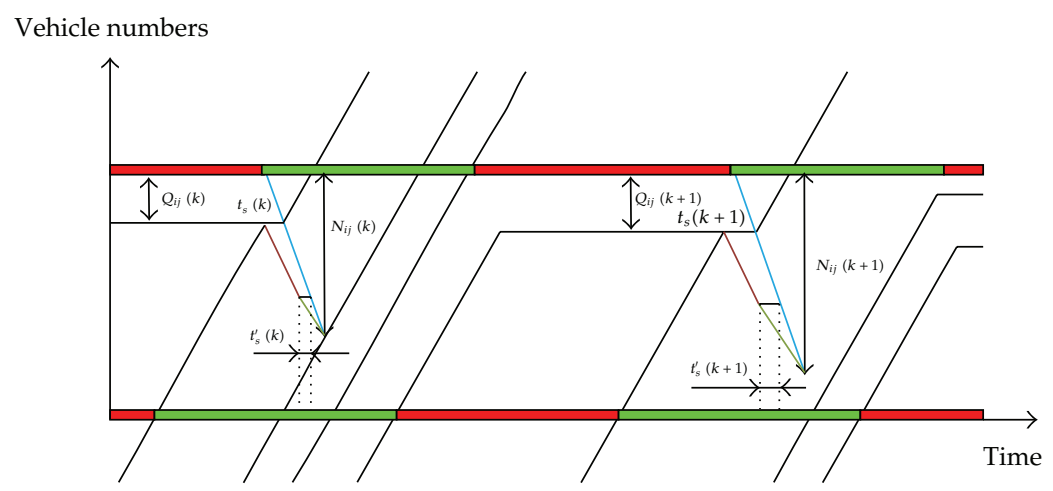

Figure 4: Arterial traffic flow temporal-spatial graph in multisaturated cycle.

Step 4. The queue numbers of total flows from upstream in cycle $k$ are:

$$
\begin{aligned}
t_{s}^{\prime}(k) & =\left(n(k)-n_{1}(k)\right) \cdot h \cdot\left(\frac{1}{v_{2}}-\frac{1}{v_{3}}\right) \\
& \Longrightarrow n(k)=n_{1}(k)+\frac{t_{s}^{\prime}(k) \cdot v_{2} \cdot v_{3}}{\left(v_{3}-v_{2}\right) \cdot h} .
\end{aligned}
$$

Then the maximum queue numbers in cycle $k$ can be calculated as

$$
N_{i j}(k)=Q_{i j}(k)+n_{1}(k)+\frac{t_{s}^{\prime}(k) \cdot v_{2} \cdot v_{3}}{\left(v_{3}-v_{2}\right) \cdot h}
$$

Step 5. We can get the variable quantity of maximum queue numbers according to (3.12):

$$
\begin{aligned}
\Delta N_{i j} & =N_{i j}(k+1)-N_{i j}(k) \\
& =\Delta Q_{i j}+\left[n_{1}(k+1)-n_{1}(k)\right]+\frac{v_{2} \cdot v_{3}}{\left(v_{3}-v_{2}\right) \cdot h}\left[t_{s}^{\prime}(k+1)-t_{s}^{\prime}(k)\right],
\end{aligned}
$$

then

$$
\Delta N_{i j}=\Delta Q_{i j} \cdot\left[1+\frac{v_{2} \cdot v_{3}}{v_{3}-v_{2}}\left(\frac{1}{v_{1}}+\frac{1}{v_{i j}}\right)\right] .
$$

The maximum queue numbers and original queue numbers of the last saturated cycle can be represented by the following equation:

$$
\begin{aligned}
& Q_{i j}(\delta)=Q_{i j}(1)+(\delta-1) \Delta Q_{i j}, \\
& N_{i j}(\delta)=N_{i j}(1)+(\delta-1) \Delta N_{i j} .
\end{aligned}
$$




\subsection{Offset Optimization Model}

Through building a single cycle function relationship between offset and maximum queue length, a computation model of queue length diversification each cycle during duration of saturated, we propose an arterial offset optimization model based on an objective of minimizing queue length over the whole duration of the saturated traffic environment, avoiding queue spillover.

Equation (3.16) builds the relationship between $N_{i j}(\omega)$ and $\phi_{i j}$. If other parameters are known, an optimal offset $\phi_{i j}^{\text {opt }}$ by simple iterative method can be obtained:

$$
\begin{aligned}
& \min \quad N_{i j}(\omega)=\frac{\left[\phi_{i j}-g_{s}(i)-L_{i j} / v_{i j}+\left(Q_{i j}+S \cdot g_{s}(i)\right) \cdot h\left(1 / v_{i j}+1 / v_{2}\right)\right]}{h \cdot\left(1 / v_{2}-1 / v_{3}\right)} \\
& +(\delta-1) \cdot \Delta Q_{i j} \cdot\left[1+\frac{v_{2} \cdot v_{3}}{v_{3}-v_{2}}\left(\frac{1}{v_{1}}+\frac{1}{v_{i j}}\right)\right], \\
& \text { s.t. } \quad x_{\mathrm{WES}}=\frac{q_{\mathrm{W}} C_{o}}{g_{\mathrm{WES} S}}>0.9 \quad \text { (a) } \\
& N_{i j} \geq Q_{i j} \quad \text { (b) } \\
& -g_{\mathrm{WES}}(j) \leq \phi_{i j} \leq C-g_{\mathrm{WES}} \quad \text { (c) }
\end{aligned}
$$

\section{Simulation Testing and Analysis}

In order to verify the application effect of the Saturated Arterial Optimization method, we simulate traffic operation state of two intersections adopting single point control (Scheme 1), coordination control (Scheme 2), and optimization coordination control (Scheme 3) by the VISSIM software, also comparative analysis of the output evaluation of these simulation scenarios.

\subsection{Simulation Testing Scheme}

Simulation Testing Arterial Schematic as shown in Figure 5: all approaches are with dedicated left turn traffic lane and they do not have the slip/slide right turn lane because we have not taken right-turning vehicles into consideration when modeling. Designing an arterial of approach $L_{i j}=400 \mathrm{~m}$, mean queue discharge headway $h=6 \mathrm{~m}$, mean travel speed $v_{i j}=$ $40 \mathrm{~km} / \mathrm{h}$, saturation flow rate $S=1800 \mathrm{veh} / \mathrm{h}$, all entry turning movement proportions of intersection $p_{\mathrm{W}}=p_{\mathrm{E}}=0.15, p_{\mathrm{N}}=p_{\mathrm{S}}=0.3$.

All entry volumes and approach lengths of arterial are showed in Table 1: assumed road section length between intersection $i$ and $j$ is $400 \mathrm{~m}$, and assumed related traffic volumes are $1794 \mathrm{veh} / \mathrm{h}$ and $128 \mathrm{veh} / \mathrm{h}$.

Assume the saturated duration of two intersections is $1200 \mathrm{~s}$, total loss time $L=12 \mathrm{~s}$, the timing scheme of three different simulation scenarios can be obtained (see Table 2).

\subsection{Discussion of Simulation Results}

Output the maximum queue length, and mean queue length, mean vehicle delays of two intersections with the three timing schemes in the last saturated cycle. 


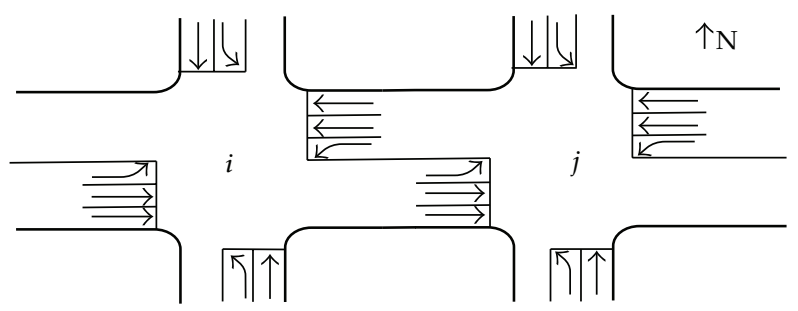

Figure 5: Simulation testing arterial schematic.

Table 1: All entry flows and approach length of the arterial.

\begin{tabular}{|c|c|c|c|c|}
\hline \multirow{2}{*}{ Direction } & \multicolumn{2}{|c|}{ Intersection $i$} & \multicolumn{2}{|c|}{ Intersection $j$} \\
\hline & Volumes (veh/h) & Approach length (m) & Volumes (veh/h) & Approach length $(\mathrm{m})$ \\
\hline \multicolumn{5}{|c|}{ East approach } \\
\hline Through & - & 325 & 1738 & 400 \\
\hline Left turn & 一 & - & 242 & - \\
\hline \multicolumn{5}{|c|}{ West approach } \\
\hline Through & 1794 & 400 & - & 400 \\
\hline Left turn & 269 & 一 & 一 & 一 \\
\hline \multicolumn{5}{|c|}{ North approach } \\
\hline Through & 298 & 275 & 400 & 425 \\
\hline Left turn & 128 & 一 & 171 & 一 \\
\hline \multicolumn{5}{|c|}{ South approach } \\
\hline Through & 272 & 300 & 498 & 355 \\
\hline Left turn & 119 & - & 213 & - \\
\hline
\end{tabular}

As shown in Table 3, when using optimized offset, the maximum queue length of link is $263 \mathrm{~m}$, less than the maximum queue length of Scheme 1 and Scheme 2, which decreased by $10.8 \%$ compared with Scheme 2 . Mean queue length is also decreased by $15.3 \%$. The maximum queue length simulation results of objective link during the saturated period are shown in Figure 6. In addition, when running the timing parameters of Scheme 3 , mean vehicle delays of coordination phase remain fixed compared with the first two schemes. In particular, maximum queue length, mean queue length, and mean vehicle delays of noncoordination phase have different degrees of improvement. Therefore, to ensure the operation parameters of competitive phase not deteriorated, the offset which is calculated by our optimization method can effectively reduce the maximum queue length and prevents queuing spillover in the approach of coordination phase.

\subsection{Sensitivity Analysis}

There is a function of offset and maximum queue length, and determining the offset reasonably can reduce the maximum queue length. Whether this optimization of different arrival rates significant or not, which requires the sensitivity analysis.

As the shown in Figure 7, with volumes increasing, the effectiveness which adjusts offset to reduce maximum queue length is more significant. But not volumes the larger the better, when volumes ratios (the ratio of volume and saturation flow rate) are $0.525-$ 0.6 , avoiding queuing spillover by optimizing offset; volumes ratio above 0.6 , adjusting offset 
Table 2: Signal timing parameters of the 3 simulated schemes.

\begin{tabular}{|c|c|c|c|c|c|c|}
\hline & \multicolumn{2}{|c|}{ Scheme 1} & \multicolumn{2}{|c|}{ Scheme 2} & \multicolumn{2}{|c|}{ Scheme 3} \\
\hline & $\begin{array}{c}\text { Intersection } \\
i \\
\end{array}$ & $\begin{array}{c}\text { Intersection } \\
j\end{array}$ & $\begin{array}{c}\text { Intersection } \\
i \\
\end{array}$ & $\begin{array}{c}\text { Intersection } \\
j\end{array}$ & $\begin{array}{c}\text { Intersection } \\
i\end{array}$ & $\begin{array}{c}\text { Intersection } \\
j\end{array}$ \\
\hline Cycle length (m) & 193 & 176 & 193 & 193 & 193 & 193 \\
\hline W-E through green (s) & 102 & 91 & 102 & 93 & 102 & 93 \\
\hline W-E left-turn green (s) & 31 & 27 & 31 & 28 & 31 & 28 \\
\hline N-S through green (s) & 34 & 41 & 34 & 42 & 34 & 42 \\
\hline N-S left-turn green (s) & 15 & 17 & 15 & 18 & 15 & 18 \\
\hline Offset (s) & \multicolumn{2}{|c|}{-} & \multicolumn{2}{|c|}{36} & \multicolumn{2}{|c|}{-31} \\
\hline
\end{tabular}

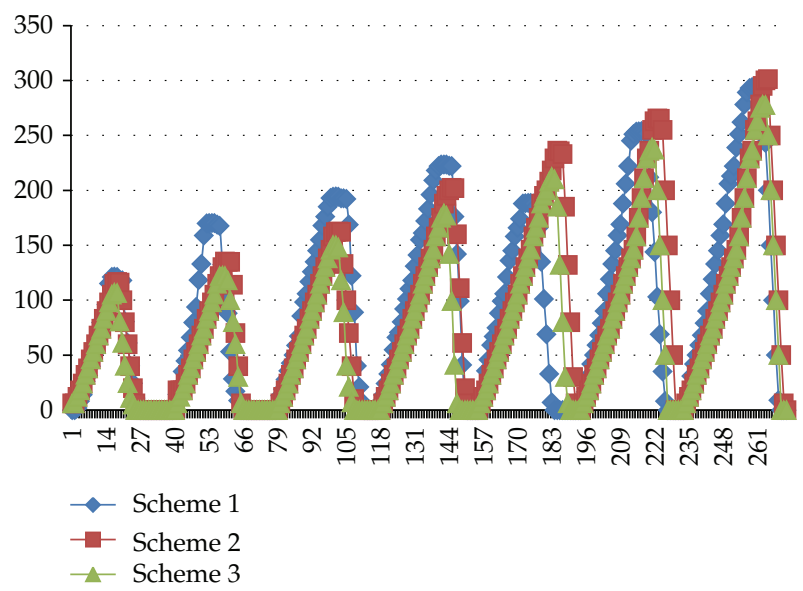

Figure 6: Simulation results of link maximum queue length.

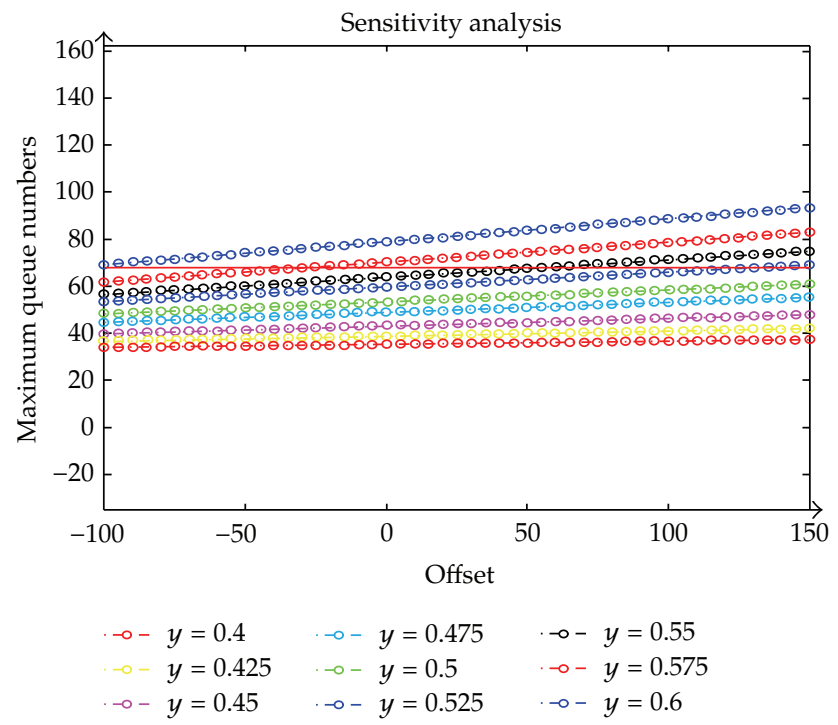

Figure 7: The relation between offset and maximum queue length. 
Table 3: Outputs parameters of the simulations.

\begin{tabular}{lccc}
\hline & Scheme 1 & Scheme 2 & Scheme 3 \\
\hline Intersection $i$ & & & \\
$\quad$ Coordination phase & 221 & 208 & 202 \\
$\quad$ Maximum queue length (m) & 113 & 101 & 96 \\
Mean queue length (m) & 108 & 100 & 88 \\
$\quad$ Mean vehicle delays (s) & & & \\
Mean value of noncoordination phase & 121 & 98 & 32 \\
$\quad$ Maximum queue length (m) & 64 & 42 & 58 \\
$\quad$ Mean queue length (m) & 78 & 64 & \\
$\quad$ Mean vehicle delays (s) & & & 263 \\
Intersection $j$ & 289 & 295 & 134 \\
Coordination phase & 162 & 170 & 128 \\
$\quad$ Maximum queue length (m) & 125 & 127 & 66 \\
Mean queue length (m) & & 132 & 80 \\
$\quad$ Mean vehicle delays (s) & 141 & 75 & \\
Mean value of noncoordination phase & 89 & 83 & \\
$\quad$ Maximum queue length (m) & 88 & & \\
Mean queue length (m) & & & \\
Mean vehicle delays (s) & & & \\
&
\end{tabular}

alone cannot reduces the queue length, spillover is inevitable, and we should consider to adjust cycle length or green time.

\section{Conclusions}

We have presented a method of offset optimization based on queue length constraint for the saturated arterial, whose objective is to minimize queue length and avoid queue spillback over the whole duration of saturated. To avoid secondary queues, in algorithm development we assume that through flows from upstream are pulse discharge to downstream. VISSIM simulation results show the follwing: to ensure the operation parameters of the competitive phase to not be deteriorated, the offset which is calculated by our optimization method can effectively reduce the maximum queue length and prevent queuing spillover. In addition, sensitivity analysis of the model shows that, before the volumes ratios exceed the threshold, the effectiveness by adjusting offset to reduce maximum queue length is less significant when volumes increase. The next step will be focused on an in-depth study timing parameter of coordinated optimization strategy for the saturated arterial.

\section{Acknowledgment}

This work was supported by the National Science Foundation of China (Grant no. 50908100, Grant no. 51278520, and Grant no. 51278220) and China Postdoctoral Science Foundation funded project (Grant no. 20110491307). The authors thank anonymous reviewers for their valuable input and suggestions.

\section{References}

[1] N. H. Gartner, J. D. C. Little, and H. Gabbay, "Optimization of traffic signal settings by mixed integer linear programming," Transportation Science, vol. 9, pp. 321-343, 1975. 
[2] N. H. Gartner, S. F. Assman, F. Lasaga, and D. L. Hou, "A multi-band approach to arterial traffic signal optimization," Transportation Research Part B, vol. 25, no. 1, pp. 55-74, 1991.

[3] C. K. Wong and S. C. Wong, "A lane-based optimization method for minimizing delay at isolated signal-controlled junctions," Journal of Mathematical Modelling and Algorithms, vol. 2, no. 4, pp. 379406, 2003.

[4] J. Chang, B. Bertoli, and W. Xin, "New signal control optimization policy for oversaturated arterial systems," in Proceedings of the Transportation Research Board 89th Annual Meeting, Washington, DC, USA, 2010.

[5] A. L. Ghassan and F. B. Rahim, "Genetic algorithms for traffic signal control and queue management of oversaturated two-way arterials," Transportation Research Record, no. 1727, pp. 61-67, 2000.

[6] D. C. Gazis and R. Herman, "The moving and phantom bottleneck," Transportation Science, vol. 26, no. 3, pp. 223-229, 1992.

[7] G. F. Newell, "A moving bottleneck," Transportation Research Part B, vol. 32, no. 8, pp. 531-537, 1998.

[8] Z. K. Khatib and G. A. Judd, "Control strategy for oversaturated signalized intersections," in Proceedings of the Transportation Resesrch Board 80th Annual Meeting, Washington, DC, USA, 2001.

[9] A. L. Ghassan and F. B. Rahim, "Development of traffic control and queue management procedures for oversaturated arterials," Transportation Research Record, no. 1603, pp. 119-127, 1997.

[10] Y. T. Wu and C. H. Ho, "The development of Taiwan arterial traffic-adaptive signal control system and its field test: a Taiwan experience," Journal of Advanced Transportation, vol. 43, no. 4, pp. 455-480, 2009.

[11] A. Sharma, D. M. Bullock, and J. A. Bonneson, "Input-output and hybrid techniques for real-time prediction of delay and maximum queue length at signalized intersections," Transportation Research Record, no. 2035, pp. 69-80, 2007.

[12] J. Walmsley, "The practical implementation of SCOOT traffic control systems," Traffic Engineering $\mathcal{E}$ Control, vol. 23, no. 4, pp. 196-199, 1982.

[13] T. H. Chang and J. T. Lin, "Optimal signal timing for an oversaturated intersection," Transportation Research Part B, vol. 34, no. 6, pp. 471-491, 2000.

[14] E. B. Lieberman, J. Chang, and E. S. Prassas, "Formulation of real-time control policy for oversaturated arterials," Transportation Research Record, no. 1727, pp. 77-78, 2000.

[15] W. H. Wang, Vehicle's Man-Machine Interaction Safety and Driver Assistance, China Communications Press, Beijing, China, 2012.

[16] H. W. Guo, W. H. Wang, W. W. Guo, X. B. Jiang, and H. Bubb, “Reliability analysis of pedestrian safety crossing in urban traffic environment," Safety Science, vol. 50, no. 4, pp. 968-973, 2012.

[17] D. H. Wang, Y. M. Bie, X. M. Song, and H. S. Qi, "Maximum cycle length optimization method of signalized intersection," Journal of Jilin University, vol. 40, no. 1, pp. 148-151, 2010.

[18] R. P. Roess and W. R. McShane, Traffic Engineering, Prentice-Hall, Englewood Cliffs, NJ, USA, 2nd edition, 1990.

[19] D. H. Wang, Traffic Flow Theory, China Communications Press, Beijing, China, 2002. 


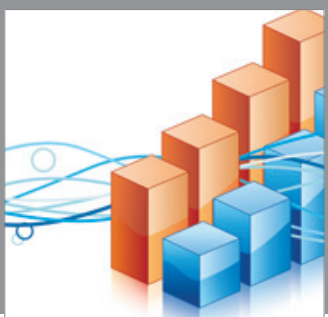

Advances in

Operations Research

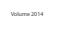

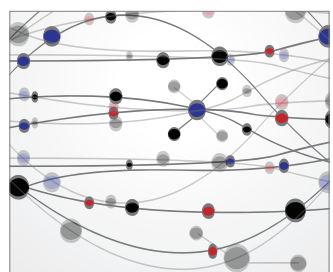

\section{The Scientific} World Journal
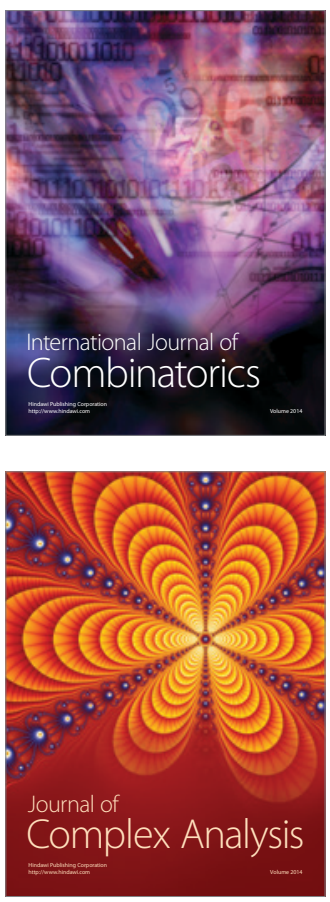

International Journal of

Mathematics and

Mathematical

Sciences
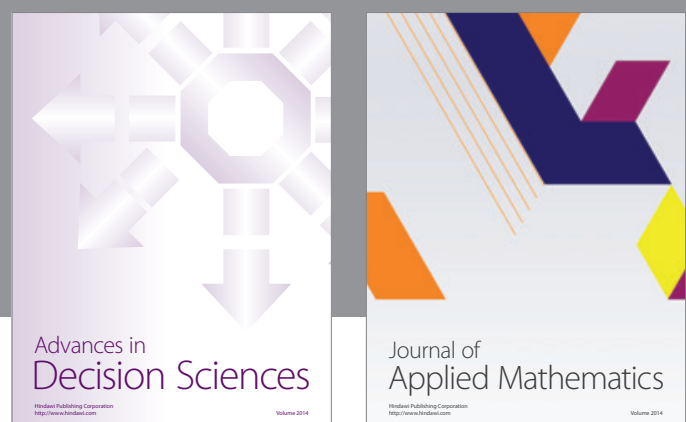

Journal of

Applied Mathematics
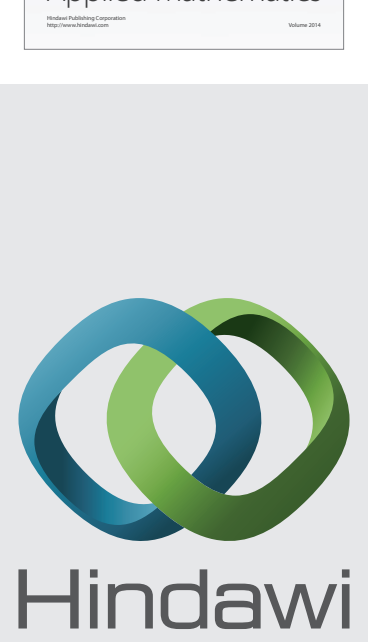

Submit your manuscripts at http://www.hindawi.com
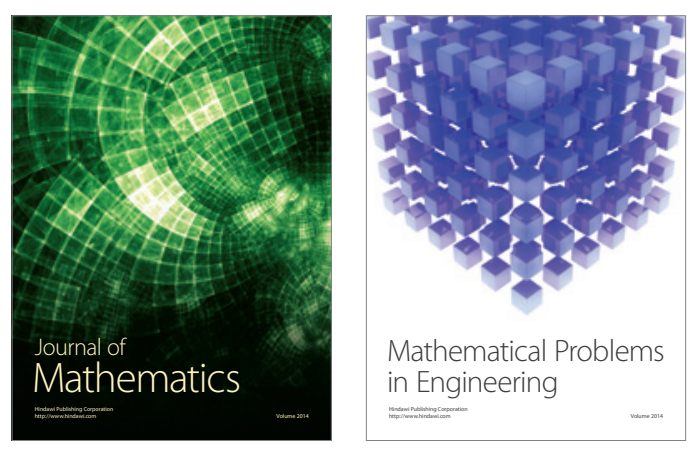

Mathematical Problems in Engineering
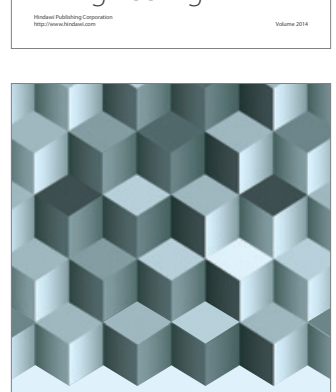

Journal of

Function Spaces
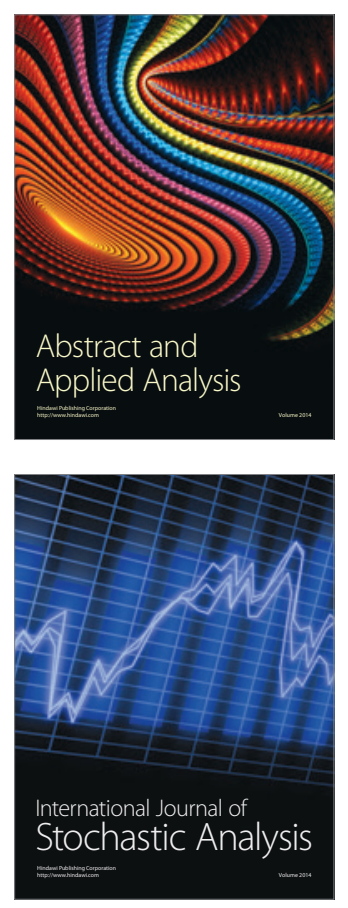

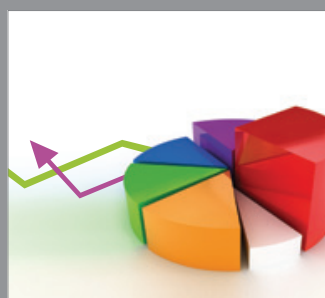

ournal of

Probability and Statistics

Promensencen
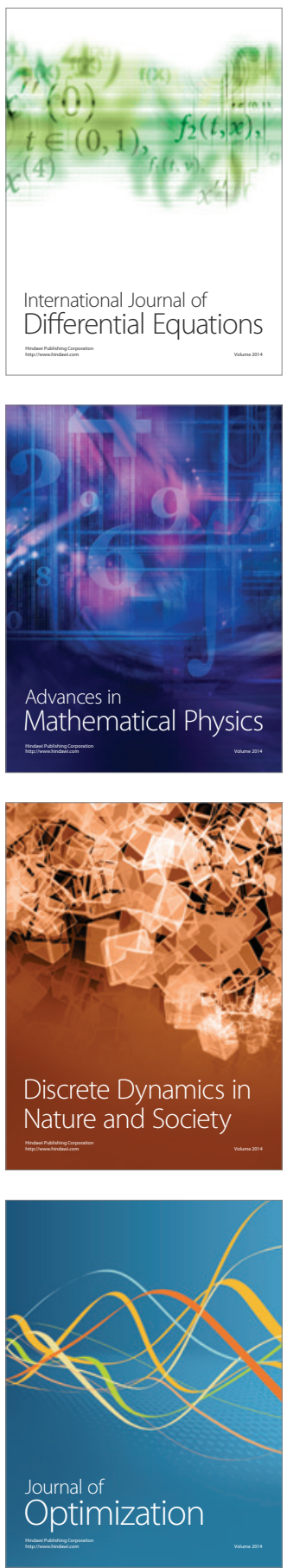